\title{
PROGRAMA CASTELLENSE DE COLETA SELETIVA DE LIXO: UM ESTUDO DE CASO DO MUNICÍPIO DE PRESIDENTE CASTELLO BRANCO (SC)
}

Priscila Cassiano de Almeida ${ }^{1}$

Cidmar Ortiz dos Santos ${ }^{2}$

Resumo: Este trabalho teve como temática um estudo de caso do Programa Castellense de Coleta Seletiva de Lixo (resíduos sólidos urbanos - RSU), desenvolvido desde o ano de 2007 no município de Presidente Castello Branco localizado no oeste de Santa Catarina. A sua implantação teve ampla participação do poder público municipal e da comunidade castellense. O objetivo principal desse trabalho é levantar informações que auxiliem os diversos atores envolvidos a julgar interesses e valores de políticas ambientais voltadas a realidade do município, para a melhoria de qualidade de vida dos cidadãos. Os resultados evidenciam a importância da responsabilidade compartilhada entre Poder Público e a população na tomada de consciência sobre a problemática do lixo.

Palavras-chave: Resíduos Sólidos Urbanos; Políticas Ambientais; Tomada de Consciência Ambiental. 


\section{Introdução}

O Programa Castellense de Coleta Seletiva de Lixo consiste na implantação da coleta seletiva de resíduos sólidos urbanos, através de parcerias de diferentes setores da Prefeitura Municipal de Presidente Castello Branco - SC. O Programa nasceu através de reuniões com a comunidade Castellense do meio rural, onde o tema lixo foi amplamente discutido devido à grande problemática que o mesmo representava, pois até o ano de 2007 (ano da implantação do Programa), não havia coleta seletiva nas comunidades do interior. A partir daí várias ações foram realizadas no sentido de sensibilizar e conscientizar toda a população sobre a correta segregação na fonte dos resíduos sólidos e a importância disso para a preservação do meio ambiente.

A implementação de programas de coleta seletiva é importante para o equacionamento dos impactos que a produção dos resíduos sólidos causa ao meio ambiente e a saúde dos cidadãos, minimizando a produção de lixo, sendo um processo viável para reutilização e reciclagem de materiais pós-consumo (SOUZA, 2012).

Conforme dados pesquisados nos arquivos da Prefeitura Municipal de Presidente Castello Branco, no ano de 2015, o Aterro Sanitário Municipal recebeu 218 toneladas de resíduos sólidos urbanos, desse montante 38\% (material reciclável) foi encaminhado para reciclagem, 59\% (rejeito) foi direcionado para a vala, e apenas $2 \%$ desse montante foi direcionado para a composteira do Aterro Sanitário.

Os dados apresentados acima revelam que o município de Presidente Castello Branco atingiu um índice bom de reciclagem e encontra-se acima da média nacional de lixo urbano reciclado, que segundo o Compromisso Empresarial para Reciclagem é de 27\% (CEMPRE, 2013).

Além disso, observa-se que o Programa está possibilitando um maior entendimento por parte dos munícipes, sobre a importância de classificar o lixo que produz e ainda contribui para uma maior aproximação das escolas com a comunidade, valorizando os projetos de Educação Ambiental desenvolvidos pelas mesmas, contribuindo na sensibilização da comunidade para os problemas ambientais, visando sua mobilização para a melhoria da qualidade de vida de todos.

Para tanto, pretende-se com esse trabalho levantar informações que auxiliem os diversos atores envolvidos no processo de educação e gestão ambiental do Programa, a julgar interesses e valores de políticas ambientais voltadas a realidade do município de Presidente Castello Branco.

\section{Panorama Geral da Coleta Seletiva nos Municípios Brasileiros}

Segundo o CEMPRE (2013), a coleta seletiva de resíduos sólidos municipais, é feita pela Prefeitura em $48 \%$ das cidades pesquisadas, empresas particulares são contratadas para realizar coleta em $26 \%$ dos casos e mais da

metade das Prefeituras (65\%) apoia ou mantém cooperativas de catadores 
como agentes executores da coleta seletiva. Cerca 766 municípios brasileiros operam programas de coleta seletiva.

Conforme relatado por Gurgel (2009), os municípios que mantiverem um programa de coleta seletiva promoverão:

- Redução de custos com a destinação de resíduos sólidos em aterros sanitários, consequentemente, aumentando a vida útil destes.

- A educação e conscientização da população;

- Melhoria nas condições ambientais e de saúde pública do município;

- Diminuição da poluição do solo, água e ar (GURGEL, 2009, p. 47).

Além disso, Gurgel (2009) defende que a implantação de programas de coleta municipais promove benefícios sociais tais como: geração de empregos diretos e indiretos, resgate social dos profissionais da reciclagem através da criação de associações/cooperativas de catadores ou até mesmo, através do trabalho autônomo de catação.

A lei no $12.305 / 2010$ prevê no art. 8으, capítulo III, a coleta seletiva, os sistemas de logística reversa e outras atividades pautadas à implementação da responsabilidade compartilhada pelo ciclo de vida dos produtos, ou seja, deve haver ato de natureza contratual firmado entre o poder público e fabricantes, importadores, distribuidores ou comerciantes, tendo em vista a implantação da responsabilidade compartilhada pelo ciclo de vida do produto.

E ainda, no que concerne a lei $\mathrm{n}^{0} 12.305 / 2010$, os municípios devem elaborar um plano de gerenciamento de resíduos sólidos o qual define um conjunto de ações exercidas, direta ou indiretamente, nas etapas de coleta, transporte, transbordo, tratamento e destinação final ambientalmente adequada dos resíduos sólidos e disposição final ambientalmente adequada dos rejeitos.

\section{Educação Ambiental no Contexto da Coleta Seletiva}

A Educação Ambiental passou a ter maior relevância e visibilidade no mundo, a partir da Conferência das Nações Unidas sobre o Meio Ambiente Humano - 1972, em Estocolmo. A Conferência teve o objetivo de alertar a humanidade sobre a importância da preservação ambiental para o bem-estar do ambiente humano e a da Educação Ambiental nesse contexto. Resultou na criação do Programa das Nações Unidas para o Meio Ambiente - PNUMA e na Política Internacional de Educação Ambiental, relacionando o pensamento ambientalista com a gestão e as políticas ambientais e econômicas (CADERNOS SECAD, 2007).

A Educação Ambiental é o principal elo para implantar programas de coleta seletiva em qualquer lugar que seja, pois deve ser utilizada como instrumento de planejamento que culmine com a mudança de hábitos e valores 
dos atores sociais (GURGEL, 2009). Corroborando com essa mesma ideia, o guia de Implantação de Coleta Seletiva para Prefeituras, elaborado pela Secretaria de Meio Ambiente da cidade de São Paulo cita o seguinte:

O processo de planejamento deve, portanto, ser acompanhado por ações de Educação Ambiental que promovam mudança de valores, práticas e atitudes individuais e coletivas para difundir e consolidar as ideias de qualidade ambiental, participação pública e cidadania (SÃO PAULO, 2005, p. 8).

É importante destacar que um Programa de Coleta Seletiva pode sucumbir ao passo que seus idealizadores se desestimularem durante 0 processo, principalmente no que diz respeito a não receptividade da população em mudar hábitos em prol de um Meio Ambiente sadio e equilibrado.

\section{Coleta Seletiva no Município de Presidente Castello Branco - Histórico e Trajetória}

Todo o lixo produzido no município de Presidente Castello Branco, até o final da década de 80 , era depositado em um terreno à céu aberto. A administração pública na época manifestou-se preocupada com essa problemática de manter um lixão a céu aberto no município, e no ano de 2000 adquiriu um terreno de $20.000 \mathrm{~m}^{2}$ a 3.500 metros de distância do centro da cidade, com o objetivo de instalar ali, o Aterro Sanitário Municipal. Durante todo o processo de construção do Aterro Sanitário, buscou-se como alternativa a terceirização da coleta que inicialmente, ocorria somente na cidade.

Com a implantação do Aterro a administração pública identificou a necessidade de desenvolver ações de conscientização com toda a população castellense. Esse processo foi dividido em três momentos imprescindíveis:

- Primeiro Momento: Trabalho de conscientização com professores da rede municipal e estadual do município.

- Segundo Momento: Planejamento entre professores e alunos com o intuito de sensibilizar a comunidade castellense (ano de 2007).

- Terceiro Momento: O poder público promoveu reuniões de sensibilização nas comunidades do interior, onde também se discutiu as necessidades e potencialidades de cada local. As principais necessidades elencadas pela comunidade foram: Lixo; Água e Dejetos Suínos. No entanto a questão da destinação do lixo produzido por cada família era o mais preocupante, e diante desta problemática nasce o Programa Castellense de Coleta Seletiva de Lixo onde a coleta seletiva se expandiu, também, para as comunidades do interior.

De início um kit composto por sacos de lixo e um folheto explicativo sobre a correta segregação dos resíduos sólidos urbanos, foi entregue às famílias castellenses. Os Kits de sacos de lixo são distribuídos até os dias de 
hoje, porém ao longo do tempo percebeu-se a necessidade premente de promover ações de conscientização e sensibilização de forma contínua e concomitante com os projetos ambientais que são desenvolvidos pelas escolas.

Um aspecto muito importante de toda essa trajetória do Programa Castellense de Coleta Seletiva, é que a comunidade sempre esteve envolvida, participando das reuniões e encontros tomando decisões em conjunto, possibilitando ainda mais uma maior efetividade das ações do Programa.

Outro aspecto importante a destacar, é o Plano de gerenciamento de resíduos sólidos do município de Presidente Castello Branco, o qual foi elaborado de forma consorciada através da Associação dos municípios do Alto Uruguai Catarinense - AMAUC.

O Plano de Gestão Integrada de Resíduos Sólidos - PGIRS constitui um dos mais importantes instrumentos da Política Nacional de Resíduos Sólidos e estabelece princípios de gestão para todos os atores envolvidos com os resíduos sólidos (produtores de mercadorias que geram resíduos nas fases de produção, consumo e pós-consumo, comerciantes, distribuidores, importadores, prestadores de serviço público ou privado de manejo de resíduos sólidos e consumidores). O plano incentiva a estruturação de programas de coleta seletiva nos municípios associados, bem como a reestruturação dos programas já existentes (SANTA CATARINA, 2014).

A elaboração do PIGIRS iniciou em 03 de Março de 2014, e foi organizado pela equipe técnica do Consórcio Intermunicipal de Gestão Ambiental Participativa do Alto Uruguai Catarinense - Consórcio Lambari, de forma consorciada entre os municípios que compõe a região da AMAUC (Associação dos Municípios do Alto Uruguai Catarinense), no qual está inserido o município de Presidente Castello Branco.

Diante disso, o plano compreende a elaboração de cinco metas. $\mathrm{Na}$ primeira meta ocorreu a criação do Portal Web, ferramenta essa voltada à informação e comunicação entre os municípios e a população em geral com a equipe técnica responsável pela elaboração do Plano. Elaborou-se também nessa meta, o Plano de Mobilização Social, o qual delimitou todas as ações que seriam tomadas no decorrer da criação do Plano.

A segunda meta compreendeu a elaboração do diagnóstico regional da situação dos resíduos sólidos dos municípios envolvidos, o qual apresentou o panorama logístico dos resíduos em todos os segmentos, desde a geração até a destinação final ambientalmente adequada, apontando as possíveis deficiências no processo de gestão.

A terceira meta apresentou a construção de arranjos regionais para a gestão consorciada de resíduos sólidos entre os municípios da região da AMAUC.

Em fevereiro de 2015, entraram em fase de elaboração as metas quatro e cinco do PIGIRS, onde a meta quatro refere-se ao planejamento e monitoramento das ações apresentada na meta três, apontando os custos da Revbea, São Paulo, V.11, № 2: 324-341, 2016. 
implantação e definindo prazos paras as mesmas serem implantadas. E a última meta (cinco) é a própria efetivação do Plano, onde será realizado um seminário integrado, abordando os diferentes segmentos dos resíduos sólidos, apresentando as soluções elencadas para a gestão integrada de resíduos sólidos na região da AMAUC.

É importante destacar que o município de Presidente Castello Branco realiza ações de Educação Ambiental e de gestão de resíduos sólidos desde o ano de 2007, conforme anteriormente destacado no presente trabalho.

O plano foi entregue no dia 09 de junho de 2015 e reuniu os gestores municipais bem como as equipes de sustentação dos municípios, numa cerimônia solene realizada na cidade de Concórdia - SC, sede da AMAUC.

\section{Atividades Desenvolvidas pelo Programa:}

\section{Reuniões nas Comunidades do Interior para Sensibilização}

No inicio das atividades do Programa Castellense de Coleta Seletiva de lixo, a administração publica em parceria com técnicos especializados promoveram diversas reuniões, a fim de sensibilizar a comunidade residente na área rural do município (Figura 1).

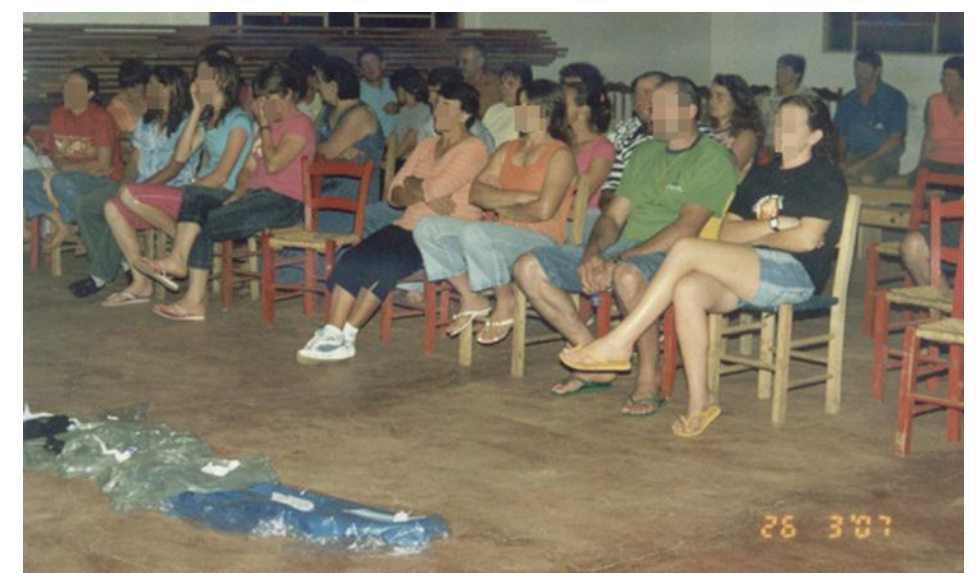

Figura 1: Reunião com a comunidade do Interior para sensibilização - Ano 2007. Fonte: Arquivo Prefeitura Municipal de Pres. Castello Branco.

\section{Formação dos professores da rede municipal e estadual de ensino}

Essa formação consistiu em planejar juntamente com os alunos, ações para sensibilizar a comunidade Castellense, em relação à problemática do lixo (Figura 2). 


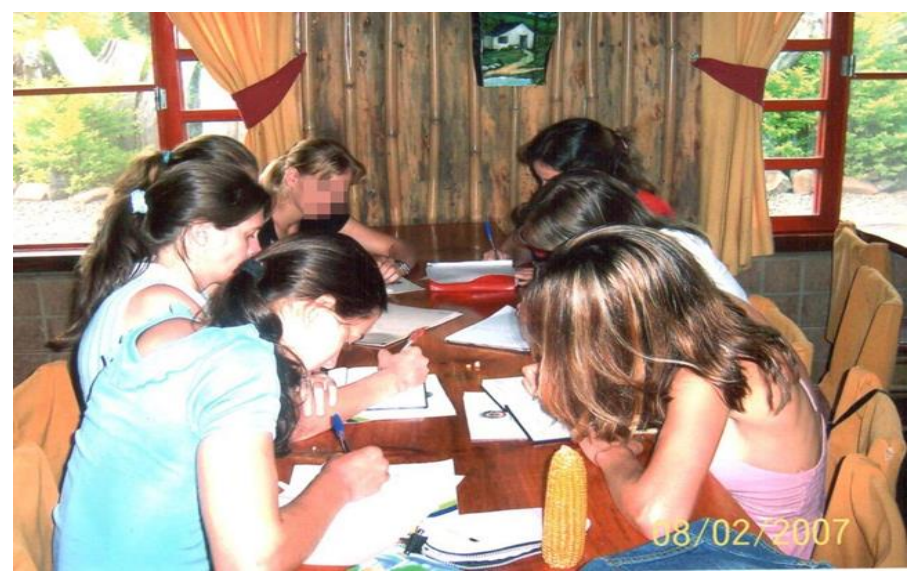

Figura 2: Formação dos Professores da rede municipal de ensino- Ano 2007. Fonte: Arquivo Prefeitura Municipal de Pres. Castello Branco.

\section{Parceria com as escolas municipais através do Projeto Educando para a Sustentabilidade}

Esse projeto macro (Educando para a Sustentabilidade) é desenvolvido nas seis escolas da rede municipal de ensino, sendo que quatro delas são escolas do campo. Cada escola desenvolve um subprojeto concomitante com a sua realidade, conforme destacado na Tabela 1 (próxima página).

Desde o início das atividades do Programa Castellense de Coleta Seletiva, as escolas municipais estiveram envolvidas em desenvolver atividades de sensibilização com a comunidade.

No mês de outubro de 2013 a Escola Municipal Centro Educacional realizou uma atividade interativa com a comunidade (clube de mãe e grupo de idosos do município) a fim de socializar o subprojeto: Biodegradáveis - Uma Alternativa Sustentável, desenvolvido pela mesma. As mães receberam um minicurso de como fabricar o sabão biodegradável em casa. As crianças apresentaram a história do sabão. Um grupo de educadoras ensaiou uma linda intervenção cultural que divertiu os convidados (Figura 3).

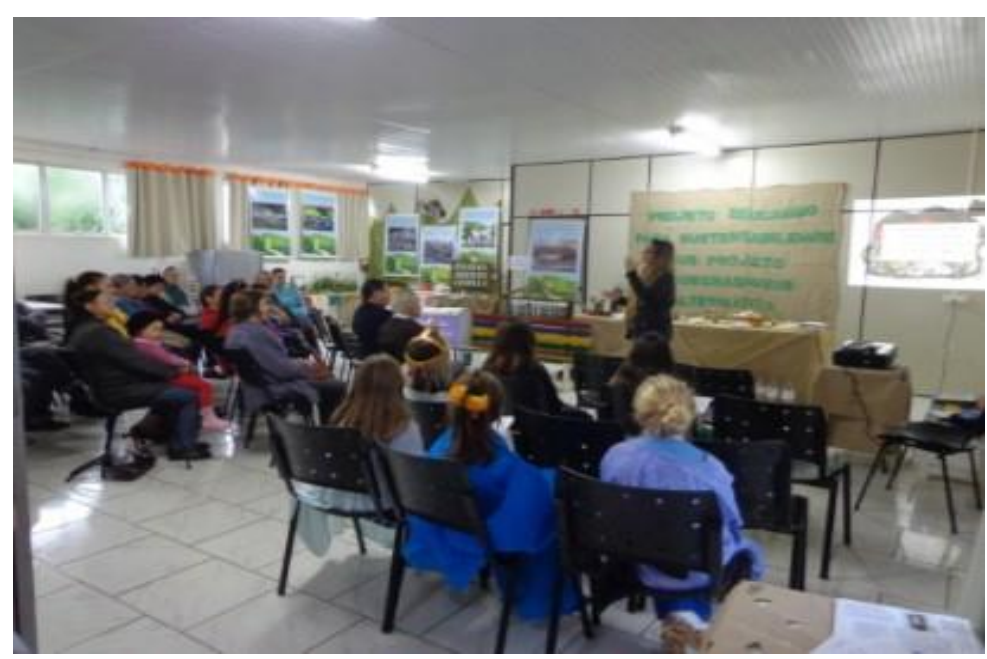

Figura 3: Alunos da escola municipal visitando o Projeto.

Fonte: Arquivos da Prefeitura Municipal.

Revbea, São Paulo, V.11, № 2: 324-341, 2016. 
Tabela 1- Descrição dos subprojetos desenvolvidos pelas escolas municipais e que compõe o projeto macro "Educando para Sustentabilidade".

\begin{tabular}{|c|c|c|c|}
\hline $\begin{array}{l}\text { Subprojetos } \\
\text { desenvolvidos }\end{array}$ & $\begin{array}{l}\text { Respon- } \\
\text { sável }\end{array}$ & Objetivos & $\begin{array}{c}\text { Número de pessoas } \\
\text { envolvidas }\end{array}$ \\
\hline $\begin{array}{l}\text { Horta } \\
\text { Permacultural: } \\
\text { valorizando a } \\
\text { Alimentação } \\
\text { Olericultura }\end{array}$ & $\begin{array}{l}\text { Escola } \\
\text { Municipal } \\
\text { Taquaral }\end{array}$ & $\begin{array}{l}\text { Sensibilizar a comunidade escolar objetivando o cultivo } \\
\text { de olericulos e o manejo de uma horta escolar } \\
\text { diferenciada como apoio aos preceitos da } \\
\text { sustentabilidade buscando uma maior qualidade de vida, } \\
\text { tornando a horta ao mesmo tempo uma ferramenta de } \\
\text { ensino aprendizagem para os alunos }\end{array}$ & $\begin{array}{c}\text { São aproximadamente } \\
40 \text { famílias envolvidas } \\
\text { no projeto }\end{array}$ \\
\hline $\begin{array}{l}\text { Pomar Escolar: } \\
\text { Uma Proposta de } \\
\text { Agrofloresta }\end{array}$ & $\begin{array}{l}\text { Escola } \\
\text { Municipal } \\
\text { São Luiz }\end{array}$ & $\begin{array}{l}\text { Utilizar o pomar escolar sendo uma proposta de } \\
\text { agrofloresta como diferente espaço educativo de } \\
\text { aprendizagens significativas acerca da saúde e nutrição, } \\
\text { alimentos naturais, preservação e lazer, intercalando } \\
\text { esses conhecimentos com toda a comunidade escolar. }\end{array}$ & $\begin{array}{c}\text { São aproximadamente } \\
30 \text { famílias envolvidas } \\
\text { no projeto }\end{array}$ \\
\hline $\begin{array}{l}\text { Lavoura Familiar: } \\
\text { Valorizando a } \\
\text { Alimentação } \\
\text { Saudável }\end{array}$ & $\begin{array}{c}\text { Escola } \\
\text { Municipal } \\
\text { Banhadão }\end{array}$ & $\begin{array}{c}\text { Sensibilizar alunos, comunidade escolar e demais } \\
\text { Instituições sobre a importância da alimentação } \\
\text { saudável, valorizando, incentivando, resgatando o } \\
\text { plantio, cultivo e consumo de alimentos naturais através } \\
\text { da implantação da Lavoura Familiar na Escola e nas } \\
\text { famílias da comunidade, priorizando qualidade de vida } \\
\text { através de ações sustentáveis }\end{array}$ & $\begin{array}{c}\text { São aproximadamente } \\
10 \text { famílias envolvidas } \\
\text { com o projeto }\end{array}$ \\
\hline $\begin{array}{l}\text { Farmácia Viva: } \\
\text { Conhecendo e } \\
\text { Utilizando Ervas } \\
\text { Medicinais no } \\
\text { nosso Dia a Dia }\end{array}$ & $\begin{array}{l}\text { Escola } \\
\text { Municipal } \\
\text { Imigra }\end{array}$ & $\begin{array}{l}\text { Realizar experiência de uma Farmácia Viva, partindo dos } \\
\text { conhecimentos culturais para os científicos na utilização } \\
\text { de ervas medicinais em nosso dia a dia, contribuindo } \\
\text { para a melhoria da qualidade de vida Castellense }\end{array}$ & $\begin{array}{l}\text { São aproximadamente } \\
40 \text { famílias envolvidas } \\
\text { com o projeto }\end{array}$ \\
\hline $\begin{array}{l}\text { Biodegradáveis: } \\
\text { Uma Alternativa } \\
\text { Sustentável }\end{array}$ & $\begin{array}{l}\text { Centro } \\
\text { Educacional } \\
\text { de Ensino } \\
\text { de } 1^{\circ} \text { Grau }\end{array}$ & $\begin{array}{l}\text { Utilizar-se dos benefícios de produtos biodegradáveis e } \\
\text { de técnicas de compostagem, e seu uso no cotidiano } \\
\text { possibilitando assim a melhoria da qualidade de vida da } \\
\text { população castellense }\end{array}$ & $\begin{array}{l}\text { São aproximadamente } \\
100 \text { famílias } \\
\text { envolvidas com o } \\
\text { projeto. }\end{array}$ \\
\hline $\begin{array}{l}\text { Construindo } \\
\text { Brinquedos e } \\
\text { Jogos pedagógi- } \\
\text { cos com Material } \\
\text { Alternativo }\end{array}$ & $\begin{array}{l}\text { Centro de } \\
\text { Educação } \\
\text { Infantil } \\
\text { "Acalanto" }\end{array}$ & $\begin{array}{c}\text { Reutilizar materiais alternativos na confecção de jogos } \\
\text { pedagógicos proporcionando um ensino aprendizagem } \\
\text { significativo e que desmistifique o consumo de } \\
\text { brinquedos industrializados. }\end{array}$ & $\begin{array}{l}\text { São aproximadamente } \\
80 \text { famílias envolvidas }\end{array}$ \\
\hline
\end{tabular}

A atividade mais recente que envolveu as escolas municipais e também a escola estadual, foi a visita do Projeto itinerante da Fundação do Meio Ambiente de Santa Catarina - FATMA, ECO- ÔNIBUS (Figura 4).

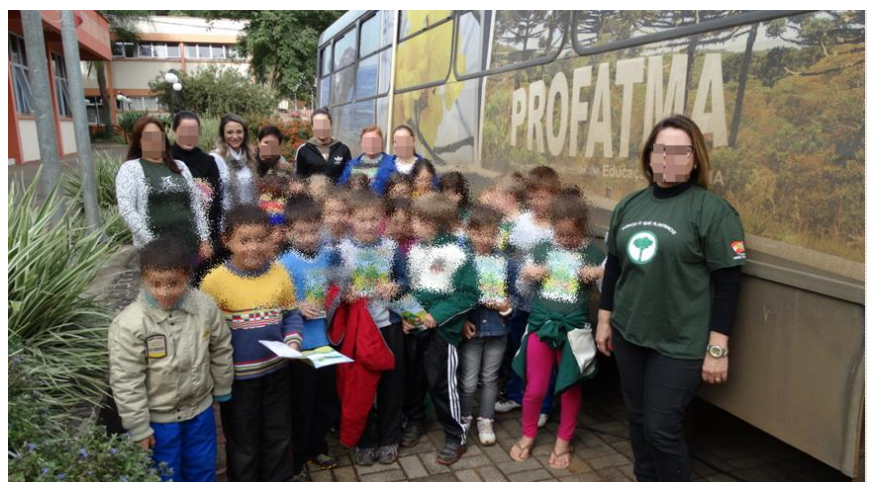

Figura 4: Alunos da escola municipal visitando o Projeto.

Fonte: O Autor. 
O ECO- ÔNIBUS é um Projeto de Educação Ambiental itinerante que iniciou no ano de 2005, desenvolvido pela FATMA (Fundação do Meio Ambiente FATMA) e tem o objetivo de desenvolver um processo de reflexão e conscientização sobre a importância da Preservação do Meio Ambiente.

O projeto é conduzido por técnicos especializados da FATMA e a metodologia utilizada baseia-se em palestras sensibilizadoras e motivadoras, com apresentação de vídeos, materiais educativos, teatro de fantoches e dinâmicas de grupo, estimulando a responsabilidade e compromisso com as questões ambientais.

\section{Ações no Aterro Sanitário Municipal}

Durante a implantação do Programa, o Aterro Sanitário Municipal passou por um processo de adequação e melhoria, como a construção do galpão de triagem e a composteira para uma disposição adequada do material orgânico (Figura 5). Devido a demanda de material orgânico recolhido na sede do município, foi necessário reestruturar a composteira (Figura 6).

Figura 5: Adequação e melhoria do Aterro Sanitário durante a implantação do Programa - Ano 2007.

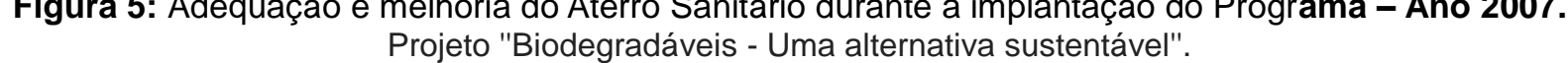

Fonte: Arquivo Prefeitura Municipal de Pres. Castello Branco atualizar a foto.
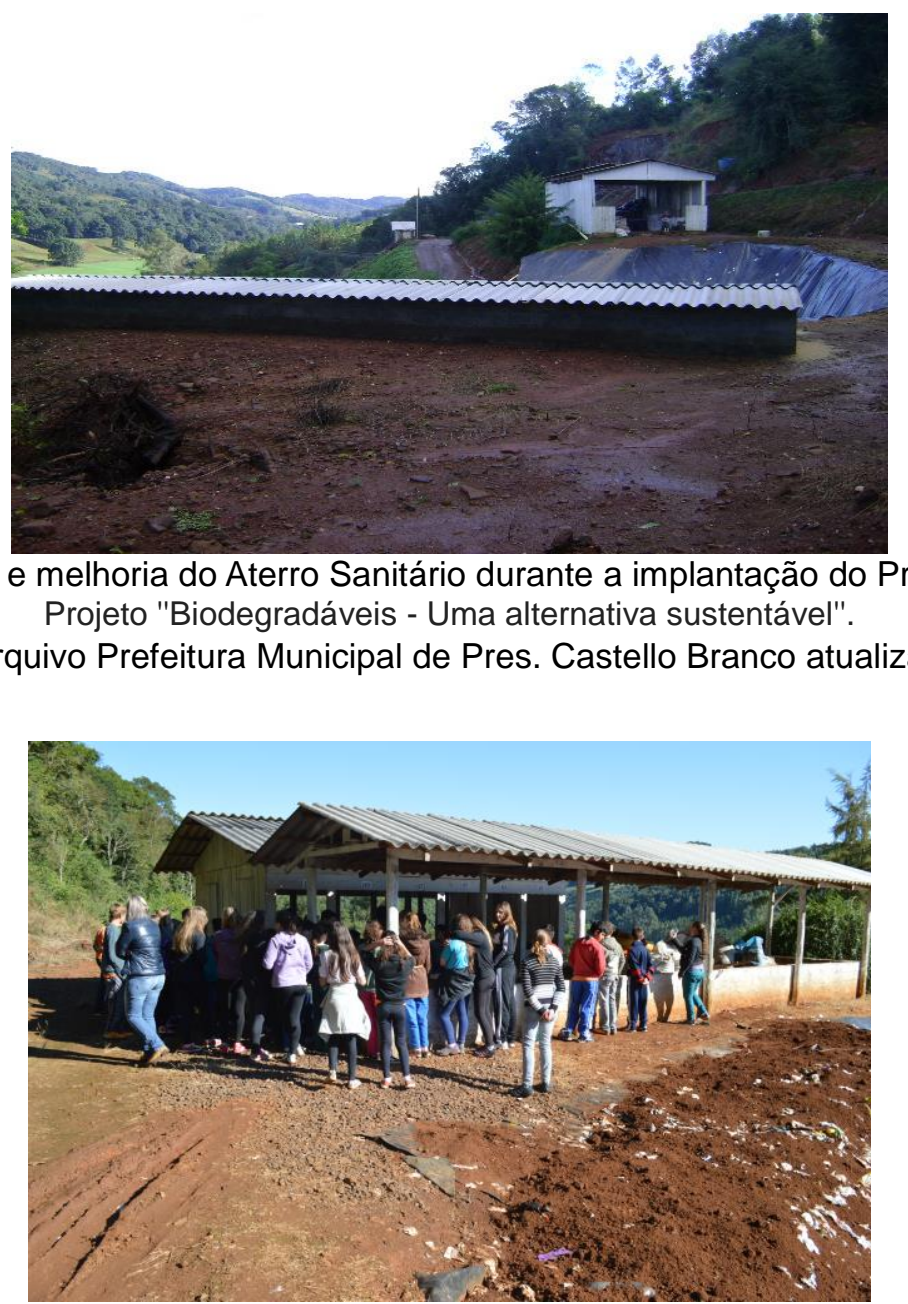

Figura 6: Ampliação da Composteira do Aterro Sanitário. Na oportunidade alunos do oitavo ano da escola estadual visitando o local. Fonte: O autor. 
Em 2009, foi implantado o Viveiro Municipal a fim de proporcionar ainda mais a valorização do material orgânico produzido pela compoteira do Aterro Sanitário (Figura 7).

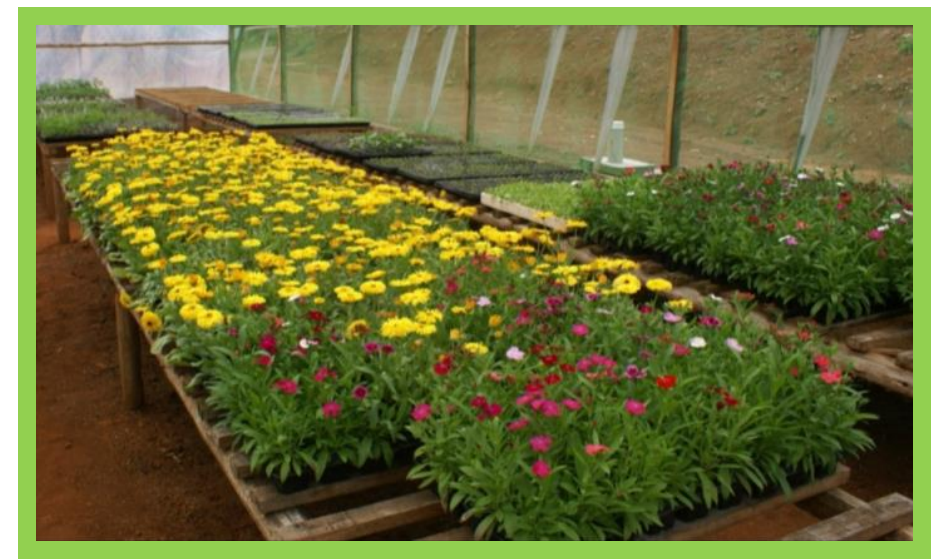

Figura 7: Viveiro Municipal no Aterro Sanitário - Ano 2009.

Fonte: Arquivo Prefeitura Municipal de Pres. Castello Branco.

Todo o material reciclável separado no centro de triagem do Aterro é vendido e o lucro é revertido em benefícios para a própria comunidade. Podese citar como exemplo a compra de climatizadores para as escolas municipais (Figura 8).

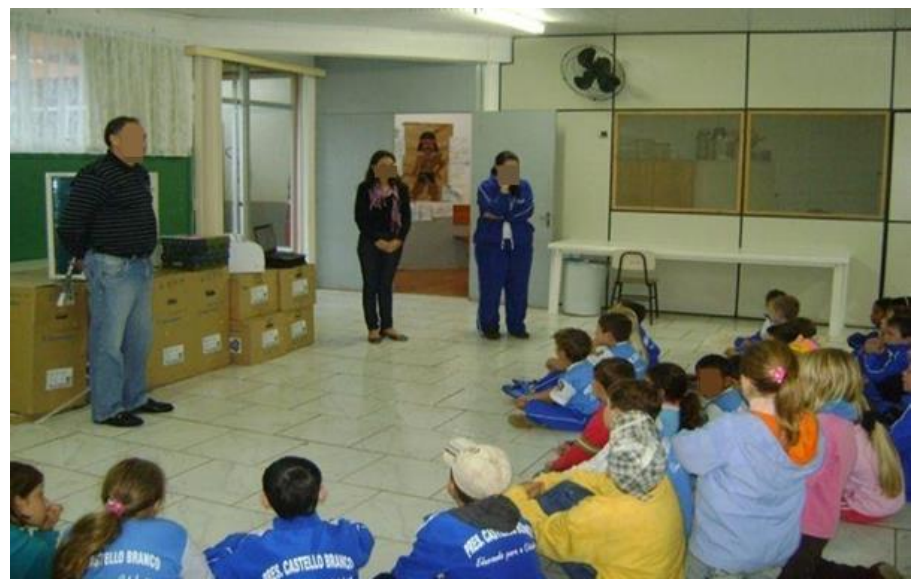

Figura 8: Entrega de Climatizadores comprados com a venda do reciclável - Ano 2008.

Fonte: Arquivo Prefeitura Municipal de Pres. Castello Branco.

\section{Projeto "A arte de Reutilizar"}

Esse projeto também fornece suporte às ações do Programa Castellense de Coleta Seletiva de Lixo. É desenvolvido, em parceria com o setor de ação social da Prefeitura Municipal. Duas costureiras contratadas pela Prefeitura dão conta de fabricar artefatos têxteis (bolsas, aventais, estopas para limpeza, almofadas etc.) reaproveitando roupas usadas descartadas pelos munícipes. As novas peças são distribuídas para visitantes e também, entre a comunidade (Figura 9). 


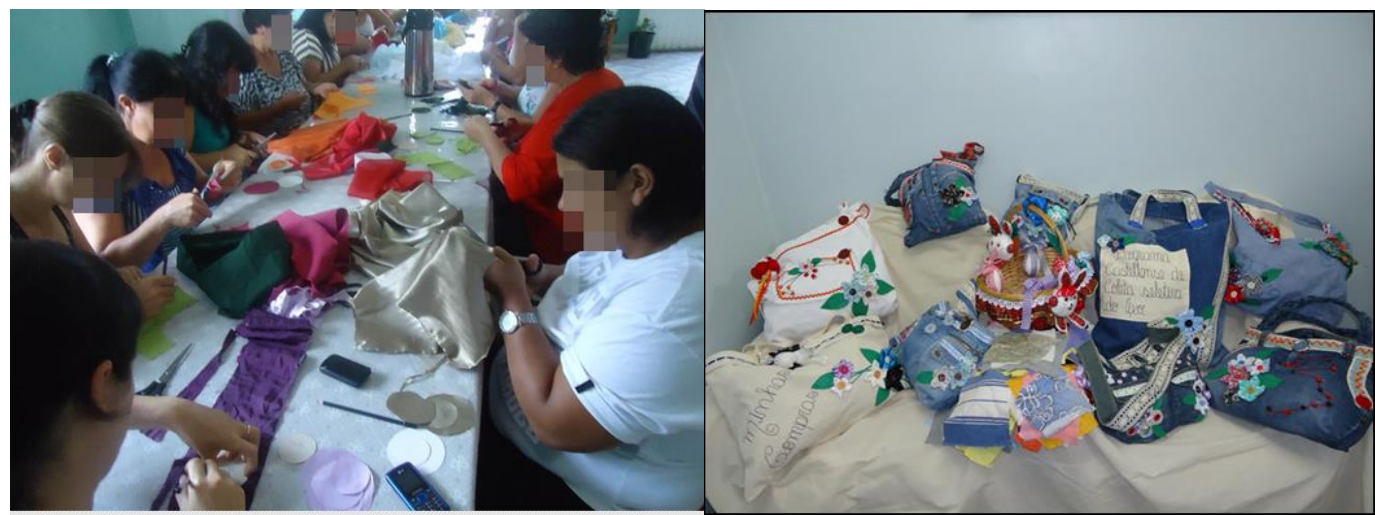

Figura 9: Bolsas confeccionadas a partir de roupas usadas descartadas "Projeto A Arte de Reutilizar". Fonte: Arquivo Prefeitura Municipal de Pres. Castello Branco.

\section{Projeto Piloto "Biocompostores Domésticos"}

O projeto piloto "Biocompostores Domésticos" trata-se de um projeto experimental a cerca da utilização de resíduos sólidos orgânicos de origem domiciliar, no processo de compostagem doméstica (Figura 10).

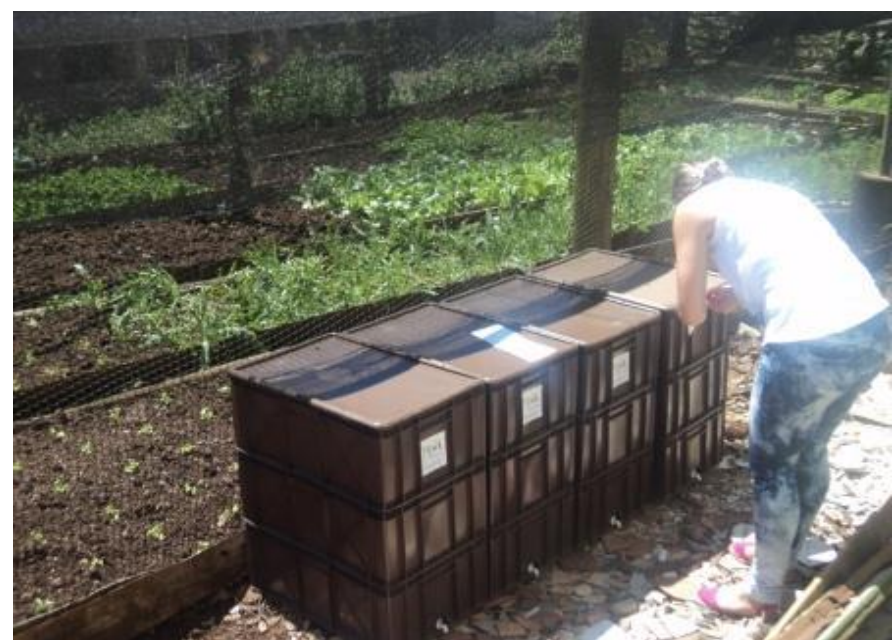

Figura 10: Implantação do Projeto piloto "Biocompostores Domésticos": Instalação de composteira. Fonte: $\mathrm{O}$ autor.

A iniciativa ocorreu a partir da parceria firmada entre a Secretaria Municipal de Educação, Cultura e Desporto e a Secretaria de Agricultura e Meio Ambiente do Município de Presidente Castello Branco. Além desses parceiros estão participando do projeto: famílias e estabelecimentos comerciais (restaurantes) do perímetro urbano do município.

A precisão de duração do Projeto experimental será de aproximadamente oito meses e terá como um de seus pilares um intenso programa de sensibilização e Educação Ambiental com a comunidade, utilizando-se de técnicos responsáveis pela orientação, bem como de materiais de divulgação e apoio, incluindo a distribuição de biocompostores e folhetos explicativos referente ao processo de compostagem. 
Como já mencionado anteriormente, a experiência de compostagem já vem sendo desenvolvida no Aterro Sanitário Municipal de Presidente Castello Branco, e por conta disso, a presente iniciativa não se torna uma grande novidade, possibilitando uma melhor aceitação por parte dos munícipes.

Em sintonia com as metas do modelo de gestão municipal, após período de experimentação, a iniciativa de implantação de biocompostores domésticos deverá ser reproduzida em todos os domicílios possíveis do Município, bem como nos comércios geradores de orgânicos presentes em todo o perímetro urbano.

Para tanto é importante que o projeto piloto inicie suas atividades com um trabalho intensificado de Educação Ambiental, através de parcerias multidisciplinares e intersetoriais, com todos os atores envolvidos no processo buscando o sucesso pleno do projeto.

\section{Criação da Lei Municipal n 1.741/2015, de 19 de outubro de 2015}

A lei Municipal $n^{\circ} 1.673 / 2013$ institui o Plano Intersetorial para 0 desenvolvimento sustentável do município de Presidente Castello Branco PIDS.

O PIDS, objetiva desenvolver programas, projetos, ações teóricas e práticas interativas, complementares, educativas, sociais, culturais, integradas, contínuas, intersetoriais, inter e transdisciplinares de Educação Ambiental permanente, que visem à qualidade de vida, em todos os segmentos públicos $\mathrm{e}$ comunitários de abrangência municipal.

O capítulo III da lei municipal $n^{0}$ 1.741/2015 refere-se a área de Resíduos Sólidos, definido como Programa Castellense de Coleta Seletiva de Lixo que abrange todo o território municipal. A lei também estabelece que o Programa dever ser desenvolvido em dois subprogramas:

a) Subprograma para Biocompostores, destinado à coleta $e$ transformação do material orgânico em adubos orgânicos nas dependências do Aterro Sanitário, incentivando e orientando também a construção e utilização de biocompostores domésticos no município;

b) Subprograma 5Rs - Repensar, Reciclar, Recusar, Reutilizar e Reduzir, com comercialização de materiais recicláveis, construção de materiais didáticos-pedagógicos, produção de produtos de limpeza e higiene, confecção de trabalhos artesanais, conscientização do uso de sacolas retornáveis e o desenvolvimento de eventos natalinos com a produção de decorações com materiais recicláveis e alternativos, fomentando a sensibilização, conscientização e orientação da população castellense a ser desenvolvido de forma intersetorial e contínua. 


\section{Metodologia}

A pesquisa foi realizada no município de Presidente Castello Branco SC O qual está localizado sob as coordenadas geográficas planas $27^{\circ}$ $13^{\prime} 31,09^{\prime \prime} S$ e 5148'14,04" O (Figura 11), ao oeste do estado de Santa Catarina na microrregião chamada Alto Uruguai Catarinense.

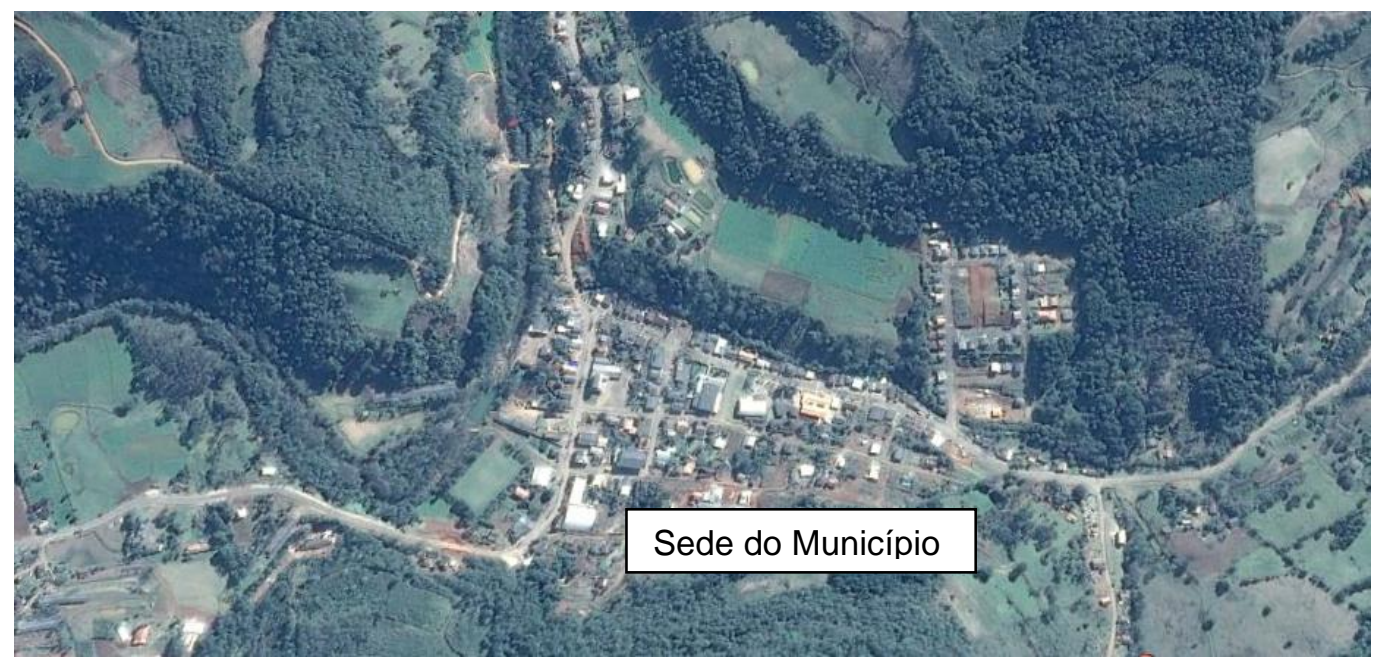

Figura 11: Imagem aérea do Município de Presidente Castello Branco.

Fonte: Google Earth, 2013.

O presente artigo seguiu a linha de pesquisa exploratória de estudo de caso e ocorreu no período de maio de 2015 a novembro de 2015 e teve como base a consulta prévia em bibliografias especializadas como trabalhos acadêmicos, artigos e informações no acervo da Prefeitura Municipal de Pres. Castello Branco.

Segundo Ellet (2008), estudos de casos são representações textuais da realidade que colocam o leitor no papel de participante da situação, a abordagem metodológica utilizada é de cunho qualitativo para a coleta e análise de dados sendo classificada como exploratória- descritiva.

A pesquisa de cunho exploratório, segundo Gil (2002) busca desenvolver, esclarecer e modificar conceitos e ideias, e habitualmente, envolver levantamento bibliográfico, não abrangendo procedimentos de amostragem e técnicas quantitativas de coleta de dados.

\section{Coleta de Dados}

A coleta de dados foi direcionada através de diferentes fontes e evidências, tais como:

1) Observação participante: Feita no decorrer do 
2) Registro fotográfico: Registro de algumas ações desenvolvidas pelo Programa.

3) Pesquisa documental: Análise e consulta de documentos e registros da Prefo recurso no valor dra Municipal de Presidente Castello Branco.

Esse trabalho foi desenvolvido com autorização prévia emitida pela Secretaria Municipal de Agricultura e Meio Ambiente da Prefeitura Municipal de Pres. Castello Branco.

\section{Análise dos Dados}

A análise de dados é a forma pela qual se obtém o significado dos diversos materiais coletados na pesquisa. Esse processo é um conjunto de idas e vindas de dados e conceitos abstratos, métodos indutivos e dedutivos, entre descrição e interpretação, produzindo os achados da pesquisa, que estabelecem descrições, temas ou categorias (MERRIAM, 1998).

Os dados coletados, para o referido projeto, procederam de forma a contemplar um universo de informações referentes a todas as ações desenvolvidas pelo Programa Castellense de Coleta Seletiva de Lixo, desde sua implantação até os dias de hoje.

Para tanto o presente estudo de caso foi avaliado de forma profunda com o objetivo de fornecer aos atores participantes e também aos munícipes, informações que os auxiliem a julgar interesses e valores de políticas ambientais voltadas a realidade do município.

\section{Público Alvo}

O Programa atende toda a população castelense. Segundo o IBGE de 2010 está em 1.725 habitantes, sendo que, cerca de 553 habitantes residem no meio urbano 1.172 no meio rural. Aproximadamente $30 \%$ da população é atendida pela coleta seletiva, três vezes por semana e aproximadamente $70 \%$ da população, correspondente aos moradores do interior, é atendida de $15 \mathrm{em}$ 15 dias.

É importante ressaltar o envolvimento das escolas que tem um papel fundamental na disseminação das práticas voltadas a preservação do meio ambiente e a valorização cultural do município.

\section{Recursos necessários para a manutenção do Programa}

Segundo o setor contábil da Prefeitura Municipal de Presidente Castello Branco os custos com a terceirização da coleta chegou ao montante de $\mathrm{R} \$ 110.000,00$ (cento e dez mil reais) ao ano. Atualmente, com a própria destinação, se gasta por ano cerca de $R \$ 72.000,00$ (setenta e dois mil reais), 
que proporciona uma economia de aproximadamente $\mathrm{R} \$ 38.000,00$ aos cofres da Prefeitura.

O valor de $R \$ 72.000,00$ anual inclui a utilização de um veículo do tipo caminhão basculante, o qual percorre três vezes por semana a área urbana e de quinze em quinze dias a área rural. Nesse valor também está incluso as 118.000 mil unidades de sacos de lixo de 15, 30,50 e 100 litros distribuídos à população no ano de 2014. No entanto, além destas despesas a prefeitura ainda arca com os custos de uma prensa hidráulica, e da equipe responsável pelo programa de coleta seletiva, que é composta de seis integrantes que correspondem a três servidores públicos que trabalham na triagem e prensagem dos materiais no Aterro Sanitário, um motorista do caminhão de coleta, uma bióloga e um engenheiro ambiental que fornecem apoio técnico no desenvolvimento das atividades no Aterro Sanitário e apoio aos trabalhos de Educação Ambiental com a comunidade Castellense.

No ano de 2015 o Programa Castellense de Coleta Seletiva foi contemplado com um recurso proveniente do Ministério Público de Santa Catarina (Fundo para Reconstituição de Bens Lesados), conforme termo de convênio no 06/2015/FRBL, processo ํo 2015/001016/FRBL, publicado no Diário Oficial Eletrônico do Ministério Público do Estado de Santa Catarina.

$O$ recurso no valor de $R \$ 96.954,00$ (noventa e seis mil novecentos e cinquenta e quatro reais) foi destinado para compra de materiais e insumos para manutenção das atividades do Programa. Com esse recurso foi comprado novas lixeiras de rua, compostores domésticos, contêineres para material reciclável, sacos de lixo para serem distribuídos, e materiais de orientação e divulgação do Programa.

\section{Principais dificuldades e limitações para implantação do Programa Castellense de Coleta Seletiva de Lixo.}

A maior dificuldade para implantação de um programa de coleta seletiva num município, ou em qualquer lugar que seja, é a falta de recursos financeiros, mas também a falta de pessoas engajadas e resilientes aptas a enfrentar os desafios propostos dentro do processo.

Segundo Aguiar; Philippi [200-], quando da elaboração e da implementação de programas de coleta seletiva, devem ser previstos estas dificuldades e os meios para eliminá-las ou minimizá-las. Mesmo quando as condições iniciais são favoráveis, é preciso manter a estrutura, os recursos e as ações ao longo do desenvolvimento dos projetos. A eficiência e a eficácia das ações devem ser monitoradas sob pena de o projeto correr o risco de não ter sucesso, ou de acabar desmobilizado.

Embora o Programa Castellense de Coleta Seletiva de lixo, já esteja disseminado por todo o município, no decorrer desse estudo identificou-se a resistência de algumas pessoas com relação ao destino que dão aos resíduos que produzem. A participação plena da população dentro do processo de 
implantação de Programas dessa dimensão é parte essencial para o seu sucesso.

Outra limitação encontrada foi em relação aos servidores municipais que prestam os serviços de coleta e triagem dos resíduos sólidos produzidos no município. Até o presente momento os servidores que desempenham as funções de coleta e triagem dos materiais recicláveis são efetivos da Prefeitura Municipal de Presidente Castello Branco. Mesmo assim a rotatividade de colaboradores é significativa, o que acaba culminando no atraso do desenvolvimento das atividades e até mesmo a sobrecarga de trabalho.

As situações apresentadas acima tornam-se fatores limitantes para que as atividades sejam desenvolvidas com sucesso. Nesse sentido é premente buscar alternativas de contratação de pessoal para trabalhar nas dependências do Aterro Sanitário bem como na coleta e triagem dos materiais, ou então formar cooperativas de forma consorciada com outros municípios pequenos.

Provavelmente o grande desafio de se manter um Programa de Coleta Seletiva funcionando em sua plenitude, é manter a energia inicial por tempo suficiente para que ocorra uma evolução ao longo prazo. Muitas vezes a ansiedade em se obter resultados imediatos, pode levar um Programa desse teor a sucumbir. Pois nem todos estão disponíveis e/ou interessados em colaborar.

\section{Resultados e Conclusões}

No que diz respeito ao componente social, acredita-se que o Programa está possibilitando uma maior aproximação das escolas com a comunidade, valorizando os projetos de Educação Ambiental desenvolvidos pelas mesmas, contribuindo na sensibilização da comunidade para os problemas ambientais, visando sua mobilização para a melhoria da qualidade ambiental tendo como consequência a melhoria da qualidade de vida de toda a comunidade Castellense.

Com relação ao componente ambiental, os resultados alcançados no quesito preservação do meio ambiente e sustentabilidade são bem satisfatórios, ainda mais quando se leva em conta que Presidente Castello Branco se encontra bem a frente de outros municípios na questão de gerenciamento de resíduos sólidos.

Cerca de $40 \%$ do total de resíduos sólidos que chegam ao aterro sanitário possuem um destino final correto, desses $40 \%, 2 \%$ são destinados para o processo de compostagem, onde o produto final se torna um adubo de boa qualidade e tal adubo é utilizado nos canteiros da cidade e no viveiro municipal, e os outros $38 \%$ são de materiais recicláveis, que são destinados à venda e os recursos voltados em benefícios para a própria comunidade. Então um valor significativo de resíduo que chega ao Aterro Sanitário Municipal possui um destino final ambientalmente correto. Esses dados garantem a continuidade do trabalho de orientação e sensibilização com a população 
castellense contribuindo para a preservação do meio ambiente garantindo melhor qualidade de vida a todos os munícipes.

Caso esse programa de gestão de resíduos sólidos não existisse, tudo que chegasse ao aterro sanitário se tornaria rejeito e iria direto para a vala e isso se tornaria um agravante para a vida útil do mesmo e ainda, aumentaria os prejuízos causados ao meio ambiente e consequentemente a saúde dos castelenses.

Para que haja uma mudança significativa de hábitos na população é premente que os atores estejam totalmente engajados no processo. Portanto a participação da comunidade na implantação do Programa Castellense de Coleta Seletiva foi fator essencial para que o Programa prosperasse e culminasse na mudança da rotina de quase toda a população.

O planejamento das ações do Programa Castellense, ao longo desses anos ocorreu de forma espaçada, sem um planejamento estratégico inicial. Para tanto sugere-se criar e manter permanentemente, uma sistemática de acompanhamento da evolução do Programa.

Acredita-se que este estudo pode ser de grande relevância para Pres. Castello Branco, pois a partir de então o município poderá tomar ciência do andamento das ações do Programa bem como aprimorar sua estrutura organizacional de forma a planejar e monitorar todas as suas ações.

É importante destacar que o Programa Castellense de Coleta Seletiva de Lixo foi ganhador de dois prêmios no ano de 2013. O primeiro prêmio celebrado pelo Programa foi 05 Prêmio Melhores Práticas da A3P do Ministério do Meio Ambiente - Destaque da Rede - Gestão de Resíduos. A segunda premiação designada ao Programa Castellense de Coleta Seletiva, foi o 21 Prêmio Expressão de Ecologia, instituído pela Editora Expressão (Troféu Onda Verde), a qual já registrou 2.160 cases inscritos, das principais empresas, ONGs, prefeituras e entidades da região Sul.

Por fim, vale destacar que o município de Presidente Castello Branco dispõe de uma política pública municipal interessada em proporcionar uma boa gestão dos resíduos sólidos urbanos e preocupa-se com a qualidade de vida da população, com a inclusão social e geração de renda dos profissionais da reciclagem, atendendo a legislação vigente.

\section{Agradecimentos}

Agradeço especialmente ao Prefeito Claudio Sartori, que gentilmente cedeu parte do acervo de documentos da Prefeitura municipal contribuindo para o desenvolvimento dessa pesquisa. 


\section{Referências}

AGUIAR, A; PHILIPPI,J.A. A ESTRUTURAÇÃO DE PROGRAMAS DE COLETA SELETIVA. In: Anais do $21^{\circ}$ Congresso Brasileiro de Engenharia Sanitária e Ambiental; São Paulo: ABES: [200-].p 10

BRASIL. Política Nacional dos Resíduos Sólidos. Lei no 12.305 de 2 de agosto de 2010. Disponível em: < http://www.planalto.gov.br/ccivil 03/ ato20072010/2010/lei/l12305.htm >. Acesso em 03 de maio de 2015

CADERNOS SECAD. Secretaria de Educação Continuada, Alfabetização e Diversidade. Educação Ambiental aprendizes de sustentabilidade. Brasília, 2007, 109 p. Apoio Ministério da Educação.

CEMPRE. O contexto histórico, a evolução e as perspectivas do mercado de resíduos recicláveis no Brasil. Review 2013. Disponível em: < file://C:/Users/ADM/Downloads/o 195a6bo8q14sdk6l1n6o1su1q0la.pdf >. Acesso em 03 de maio de 2015

ELLET, W. Manual de estudo de caso: como ler, discutir e escrever casos de forma persuasiva. (A. Vieira, Trans.) Porto Alegre: Bookman, 2008.

GIL, C. A. Como elaborar projetos de pesquisa. 4. Ed. São Paulo. Ed. Atlas, 2002

GURGEL, F.F. Participação de moradores no Programa de Coleta Seletiva em três bairros de Natal/RN: Explorando Determinantes Pisico-socioambientais. (Tese de Doutorado em Psicologia Social) Universidade Federal do Rio Grande do Norte, Natal, 2009. 216 P.

IBGE Instituto Brasileiro de Geografia e Estatística- IBGE. Censo de 2010. Disponível em:http://www.ibge.gov.br/home/estatistica/populacao/censo2010/resultados dou/defa ult resultados dou.shtm> Acesso em: 01 de maio de 2015.

MERRIAM, S. Qualitative research and case study applications in education. San Francisco: Jossey-Bass, 1998.

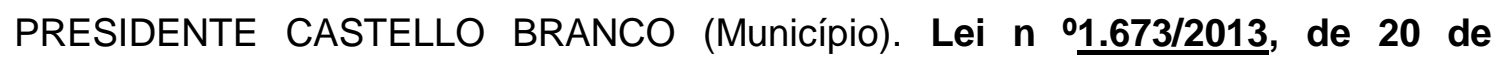
dezembro de 2013. Dispõe sobre a instituição do Plano Intersetorial para o Desenvolvimento Sustentável do Município de Presidente Castello Branco - PIDS e dá outras providências

SANTA CATARINA (Estado). Associação dos Municípios do Alto Uruguai Catarinense - AMAUC. Plano Municipal de Integrada de Resíduos Sólidos, Meta 2 Diagnóstico de Resíduos Sólidos. Concórdia, 2014. 372 p.

SANTA CATARINA. Termo de Convênio N. 06/2015/FRBL - PROCESSO N. 2015/001016/FRBL. Diário Oficial Eletrônico do Ministério Público de Santa Catarina. Disponível em

http://documentos.mpsc.mp.br/portal/manager/resourcesDB.aspx?path=1359> Acesso em 02 de junho de 2015.

SÃO PAULO (estado). Secretaria do Meio Ambiente. Coleta seletiva para prefeituras. 4.ed. São Paulo, 2005. 35p

SOUZA, R. Políticas Públicas e Resíduos Sólidos para o Município de Itapetininga-SP. Universidade De Brasília - UNB Departamento De Geografia - GEA Curso De Licenciatura em Geografia. Itapetininga-SP, 2012. 41 p. 